\title{
Restorative Treatment Thresholds: Factors Influencing the Treatment Thresholds and Modalities of General Dentists in Kuwait
}

\author{
Mai E. Khalaf ${ }^{a}$ Qasem D. Alomari ${ }^{a}$ Hien $\mathrm{Ngo}^{a}$ Sophie Doméjean ${ }^{b}$ \\ ${ }^{a}$ Department of Restorative Sciences, Faculty of Dentistry, Health Sciences Centre, Kuwait University, \\ Jabriya, Kuwait; ${ }^{b} \mathrm{CHU}$ Clermont-Ferrand, Service d'Odontologie, Clermont-Ferrand, France
}

\section{Key Words}

Restorative treatment · Dentistry · Decisions · Operative intervention

\begin{abstract}
Objectives: This study investigated the thresholds at which general dentists in Kuwait would restore approximal and occlusal carious lesions and examined the demographic characteristics of the dentists in relation to their decision making. Subjects and Methods: The study population consisted of a random sample of 185 general dentists practicing in the Ministry of Health of Kuwait. A survey questionnaire was administered. The questionnaire presented different stages and locations of carious lesions; the participants were asked to identify the stage at which a restoration is required under different conditions, the preparation technique, and their choice of restorative material. Results: For approximal carious lesions, 74 (40\%) of the participants reported that they would restoratively intervene when the carious lesion reached the outer third of the dentin. A total of 91 (49.2\%) reported the use of traditional class II restorations. For occlusal carious lesions, $128(69.2 \%)$ said they would intervene when lesions reached the middle third of the dentin. 146 (78.9\%) said they would remove the carious tissue only in
\end{abstract}

\begin{tabular}{ll}
\hline KARGER & $\begin{array}{l}\text { ( } 2014 \text { S. Karger AG, Basel } \\
1011-7571 / 14 / 0234-0357 \$ 39.50 / 0\end{array}$ \\
$\begin{array}{l}\text { E-Mail karger@karger.com } \\
\text { www.karger.com/mpp }\end{array}$ & $\begin{array}{l}\text { This is an Open Access article licensed under the terms of the } \\
\text { Creative Commons Attribution-NonCommercial 3.0 Un- } \\
\text { ported license (CC BY-NC) (www.karger.com/OA-license), } \\
\text { applicable to the online version of the article only. Distribu- } \\
\text { tion permitted for non-commercial purposes only. }\end{array}$
\end{tabular}

their preparation. For both approximal and occlusal lesions, the participants preferred resin composite as the material for restoration. Conclusions: The respondents tended to delay restorative intervention until dentinal penetration of the caries. Resin restorative materials were used in conservatively prepared cavities. Participants chose a conservative approach for occlusal lesions but still believed in a traditional approach when it concerned approximal lesions. Experience, university dental education, and participation in continuous education courses were most significantly related to restorative treatment.

(c) 2014 S. Karger AG, Basel

\section{Introduction}

The prevalence of dental caries in Kuwait is high and there is no indication of a decrease as observed in most industrialized countries $[1,2]$. Dental general practitioners are exposed to clinical cases with different stages of caries progression for which they have to decide when to monitor, apply noninvasive therapy, or restore. The decision to place a primary restoration may affect the prognosis of the tooth and the cost of treatment over the course of the tooth's lifetime [3]. 
Fig. 1. Illustration of the radiographic appearance of progressive (stages 1-6) approximal carious lesions.

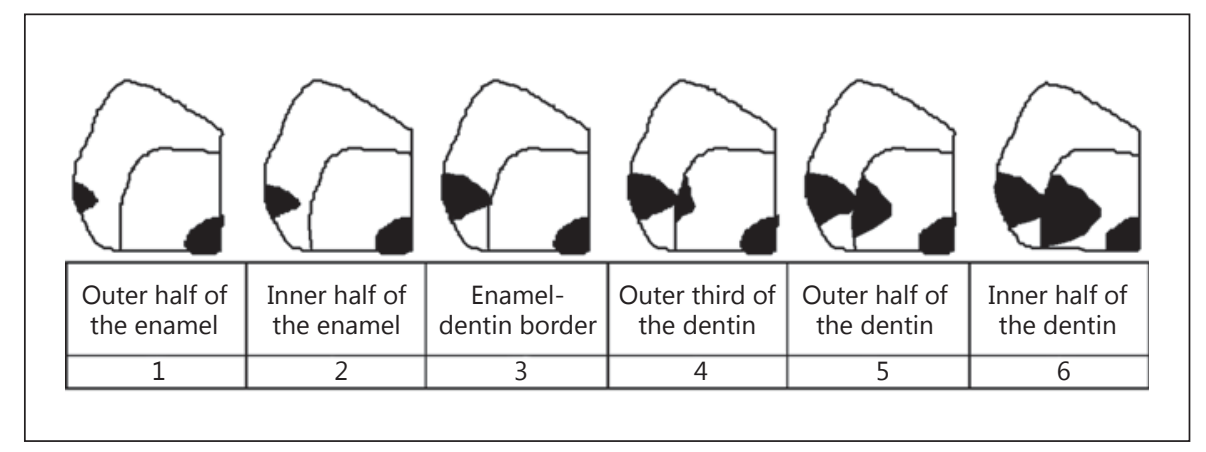

Recently, dental professionals have acquired a better understanding of the carious process, so the philosophy governing operative treatment has changed [4-7]. The universal restorative surgical approach has been replaced by minimally invasive procedures in order to preserve the greatest amount of tooth structure possible [8]. The philosophy of minimal intervention dictates that operative intervention should only be performed when cavitation is present [4]. The treatment and management of carious lesions ideally should be based on severity and activity [9]. This more conservative philosophy is based on sound science that spans the breadth of the disease continuum and includes the nonsurgical management of early noncavitated carious lesions and the use of effective conservative interventions for dental caries $[4,5,10-12]$. It is also recognized that the appropriate management of dental caries must include an early diagnosis of early noncavitated lesions and measures for their prevention and arrest [6]. In the presence of enamel surface integrity, carious lesions involving enamel and/or dentin can be managed by remineralization therapies without restorative intervention [13]. Monitoring, topical fluoride application, and fissure sealants have become the standard treatment modality for noncavitated carious lesions [14].

Great variations in treatment philosophies and strategies for carious lesions exist all around the world [11]. The large variability that exists among dentists in the management of carious lesions (diagnosis and choice of a therapy) is well known [15]. It also seems that decision making in caries management not only depends on pathophysiology but also seems to be influenced by many other factors [15]. Dentists tend to follow a set script for making a clinical decision that is not based solely on pathological and physiological observations, and the patient's oral health is not the sole determinant of clinical decisions [15]. Factors such as the dentist's age, years of experience, and educational background have been reported to affect the decision-making process [16].

The restorative treatment criteria used by dentists in the clinical setting have been studied in many countries. A wide variation in criteria between and within dentists has been shown $[16,17]$. Hence, the aims of this study were: (a) to investigate the initial point of restorative intervention in cases of occlusal and approximal caries within a random sample of general dentists, (b) to find out the type of restorative treatment delivered, and (c) to examine associations between demographic factors and restorative treatment decisions.

\section{Materials and Methods}

A total of 533 general dentists currently work in the Ministry of Health of Kuwait [18]. Two hundred were randomly selected to participate in this study. The sample size was calculated to allow for a $5 \%$ margin of error and $90 \%$ confidence intervals. Ethical approval from the Human Rights Committee and Research Committee of Kuwait University was obtained. Participants were approached in the dental clinics where they practice, and signed consent to participate in this study was obtained.

A questionnaire originally developed by Espelid and Tveit [17] was used. It collected demographic information about the participants, including their gender, age, years of experience $(1-5,6-10$, $11-15,16-20$, or $>20$ years), and region of university of graduation (Middle East, North America, Asia, or Western Europe). Dentists were also asked to indicate if they have participated in any continuing education course in cariology in the last 5 years.

The questionnaire included figures and/or photographs of different stages of carious lesions. The different radiographic stages of approximal carious lesion progression are illustrated in figure 1, while photographs of progressive occlusal carious lesions with a description of the radiographic appearance of each lesion are shown in figure 2 .

The participants were asked to identify the stage at which a restoration was required if the patient was 20 years old, visited his/her dentist once a year, had adequate oral hygiene, and used fluoridated toothpaste. For approximal lesions, the participants were 
Fig. 2. Photographs of progressive occlusal carious lesions. a No radiographic signs of lesions. b No radiographic signs of lesions. c Lesions on the outer third of the dentin on the bitewing radiograph. $\mathbf{d}$ Lesions on the middle third of the dentin on the bitewing radiograph e Lesions on the inner third of the dentin on the bitewing radiograph.

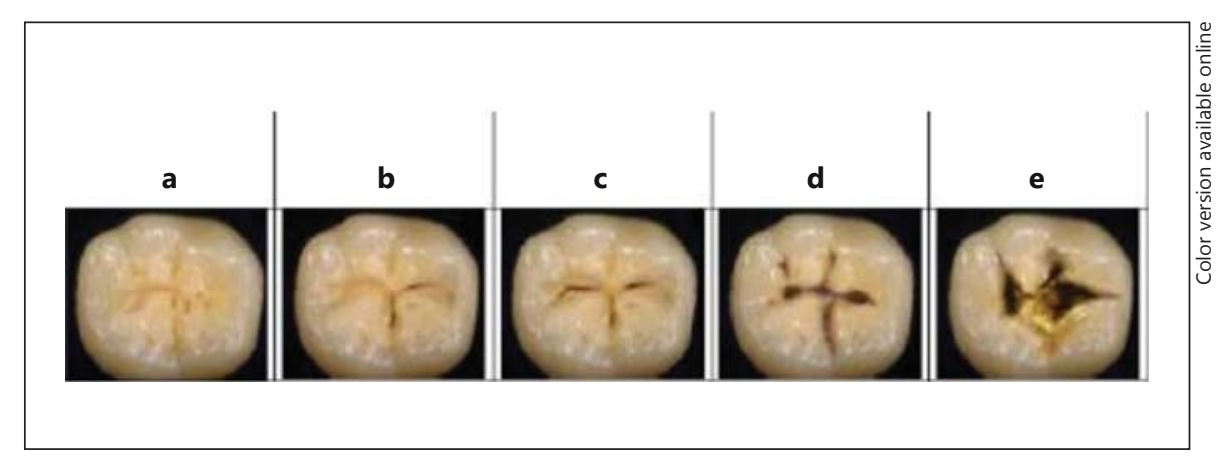

asked to identify the restorative treatment modality (traditional class II, tunnel, or saucer-shaped preparation) they would use for the management of the smallest lesion they were going to restore, assuming the lesion was situated distally on the upper second premolar. Finally, the participants were asked to identify their choice of restorative material for the smallest approximal lesion to be restored: amalgam, composite, conventional glass ionomer cement (GIC), resin-modified glass ionomer cement (RMGI), a combination of GIC and composite, or other materials. For occlusal lesions, the participants were also asked to identify the earliest stage of restorative intervention and the restorative material used.

\section{Statistical Analysis}

Data analysis was performed using the Statistical Package for the Social Sciences version 17.0 (SPSS Inc., Chicago, Ill., USA). The statistical associations between the demographic characteristics of the dentists and their restorative decisions for approximal and occlusal lesions were assessed using Pearson's $\chi^{2}$ test. Multiple correspondence analysis (MCA) was conducted to explore the strengths and structures of the associations. $\mathrm{p}<0.05$ was considered statistically significant.

\section{Results}

A total of 185 general dentists participated in this study; 93 (50.3\%) of the respondents were females. They ranged in age from 23 to 68 years, but 150 (81.1\%) were less than 40 years old. They graduated from universities in the Middle East $(\mathrm{n}=107 ; 57.8 \%)$, North America $(\mathrm{n}=$ $28 ; 15.1 \%)$, Asia ( $n=25 ; 13.5 \%)$, and Western Europe $(n=20 ; 10.8 \%)$. The number of dentists who had not pursued any continuing education courses in the field of cariology during the past 5 years was 138 (74.6\%).

\section{Approximal Carious Lesions}

Among the 185 participants, 19 (10.3\%) said they would restore a carious lesion confined to the outer or inner half of the enamel, whereas 153 (82.7\%) responded that they would wait until the lesion was in the outer third
Table 1. Restorative threshold, restorative treatment, and restoration techniques for approximal and occlusal carious development

\begin{tabular}{|c|c|c|}
\hline \multirow{7}{*}{$\begin{array}{l}\text { Earliest stage of approximal } \\
\text { carious lesions of/for } \\
\text { restorative treatment }\end{array}$} & \multicolumn{2}{|l|}{ Caries stage } \\
\hline & Outer half of the enamel & $4(2.2)$ \\
\hline & Inner half of the enamel & $15(8.1)$ \\
\hline & EDJ & $13(7.0)$ \\
\hline & Outer third of the dentin & $74(40.0)$ \\
\hline & Outer half of the dentin & 35 (18.9) \\
\hline & Inner half of the dentin & $44(23.8)$ \\
\hline \multirow{4}{*}{$\begin{array}{l}\text { Choice of preparation } \\
\text { technique for approximal } \\
\text { carious lesions }\end{array}$} & Preparation technique & \\
\hline & Traditional preparation & $91(49.2)$ \\
\hline & Tunnel preparation & $46(24.9)$ \\
\hline & Saucer-shaped preparation & $48(25.9)$ \\
\hline \multirow{6}{*}{$\begin{array}{l}\text { Choice of restorative material } \\
\text { for approximal carious lesions }\end{array}$} & Restorative material & \\
\hline & Amalgam & $21(11.4)$ \\
\hline & Composite & $113(61.1)$ \\
\hline & GIC & $13(7.0)$ \\
\hline & RMGI & $14(7.6)$ \\
\hline & Sandwich technique & $24(13.0)$ \\
\hline \multirow{5}{*}{$\begin{array}{l}\text { Earliest stage of occlusal } \\
\text { carious development at } \\
\text { intervention }\end{array}$} & Caries stage & \\
\hline & II & $8(4.3)$ \\
\hline & III & $52(28.1)$ \\
\hline & IV & $81(43.1)$ \\
\hline & $\mathrm{V}$ & $4(23.8)$ \\
\hline \multirow{7}{*}{$\begin{array}{l}\text { Choice of restorative material } \\
\text { for occlusal carious lesions }\end{array}$} & Restorative material & \\
\hline & Amalgam & $18(9.7)$ \\
\hline & Composite & $127(68.6)$ \\
\hline & GIC & $13(7.0)$ \\
\hline & RMGI & $14(7.6)$ \\
\hline & Sandwich technique & $10(5.4)$ \\
\hline & Other & $3(1.6)$ \\
\hline
\end{tabular}

Values are presented as numbers (\%).

of the dentin or deeper (table 1). The preferred preparation type for $91(49.2 \%)$ of the dentists was traditional class II, for 46 (24.9\%) it was tunnel, and for 48 (25.9\%) it was saucer-shaped. Composite resin as a restorative material was chosen by $113(61.1 \%)$ of the respondents. Amalgam was chosen by $21(11.4 \%)$, GIC was chosen by 13 
Table 2. Statistical associations between the respondents' demographic characteristics and their restorative decisions for approximal and occlusal lesions (Pearson's $\chi^{2}$ tests)

\begin{tabular}{llrc}
\hline $\begin{array}{l}\text { Decisions for } \\
\text { restorative treatments }\end{array}$ & $\begin{array}{l}\text { Demographic } \\
\text { characteristics of the } \\
\text { dentists }\end{array}$ & & p value \\
\hline $\begin{array}{l}\text { Restorative threshold for } \\
\text { approximal lesions before }\end{array}$ & Experience & 59.79 & $<0.001^{*}$ \\
intervention & Gender & 9.62 & $0.022^{*}$ \\
& University & 3.62 & 0.728 \\
& Continuing education & 12.31 & $0.006^{*}$ \\
\hline Choice of restorative & Experience & 20.56 & $0.008^{*}$ \\
treatment for approximal & Gender & 1.71 & 0.425 \\
lesions & University & 21.99 & $0.001^{*}$ \\
& Continuing education & 4.38 & 0.112 \\
\hline Choice of restorative & Experience & 44.19 & $<0.001^{*}$ \\
material for & Gender & 21.40 & $<0.001^{*}$ \\
approximal lesions & University & 21.88 & $0.039^{*}$ \\
& Continuing education & 9.91 & $0.042^{*}$ \\
\hline Restorative threshold for & Experience & 24.99 & $<0.001^{*}$ \\
occlusal lesions at & Gender & 3.11 & 0.374 \\
intervention & University & 17.98 & $<0.001^{*}$ \\
& Continuing education & 12.32 & $0.006^{*}$ \\
\hline Choice of restorative & Experience & 38.77 & $<0.001^{*}$ \\
material for occlusal & University & 34.49 & $0.001^{*}$ \\
lesions & Continuing education & 5.75 & 0.219 \\
\hline
\end{tabular}

* Significant association, $\mathrm{p}<0.05$.

(7\%), and RMGI was chosen by 14 (7.6\%) dentists, and 24 (13\%) chose to restore employing the sandwich technique which involves the use of GIC and composite material.

Occlusal Carious Lesions with Radiographic Description

None of the participants would restoratively treat teeth in the presence of discoloration of enamel without cavitation, and relatively few $(\mathrm{n}=8 ; 4.3 \%)$ chose to intervene with restorative treatment when there was a break in the enamel surface without radiographic signs of caries. The number of participants who chose to intervene restoratively when there was radiographic evidence of caries limited to the outer third of the dentin was $5(2.7 \%)$, whereas 44 (23.8\%) chose not to intervene until the lesion was in the inner third of the dentin on the radiograph. When choosing the type of restorative treatment, 146 (78.9\%) of the participants said they would remove the carious tissue only in the most conservative manner (without the use of standardized preparation shapes). Composite was the preferred restorative material among 127 (68.6\%) of the participants. Amalgam was chosen by
18 (9.7\%), GIC was chosen by 13 (7\%), and RMGI was chosen by $14(7.6 \%)$ dentists, and $10(5.4 \%)$ chose to restore employing the sandwich technique which involves the use of GIC and composite material, while 3 (1.6\%) chose to restore with other restorative materials not stated above.

\section{Associations between Demographic Factors and \\ Restorative Treatment Decisions}

The statistical associations between the demographic characteristics of the respondents and their restorative decisions for both approximal and occlusal lesions as indicated by Pearson's $\chi^{2}$ tests are presented in table 2 . The $\chi^{2}$ tests indicated that decisions concerning the earliest stage of approximal carious development for restorative intervention were significantly associated with the years of experience $(p<0.001)$, the gender $(p=0.022)$, and the continuing education $(p=0.006)$ of the dentists. The choice of preparation technique for approximal carious development was significantly associated with the years of experience $(p=0.008)$ and the years of university education ( $p=0.001)$ of the dentists. The choice of restorative material for approximal carious development was significantly associated with the years of experience $(\mathrm{p}<0.001)$ and the university $(\mathrm{p}<0.039)$ and continuing education $(\mathrm{p}=0.042)$ of the dentists. The earliest stage of occlusal carious development at intervention was significantly associated with the years of experience $(\mathrm{p}<0.001)$, the university $(\mathrm{p}<0.001)$, and the continuing education $(\mathrm{p}=$ 0.006) of the dentists. The choice of restorative material for occlusal carious lesions was significantly associated with the years of experience $(p<0.001)$ and the university $(\mathrm{p}=0.001)$ of the dentists.

MCA indicated that dentists with 1-5 years of experience tended to choose the enamel-dentin junction (EDJ) as the earliest stage of approximal carious development at which they would intervene, and dentists with 11-20 years of experience tended to choose the outer and inner half of the dentin, whereas dentists with $>20$ years of experience tended to choose the outer and inner half of the enamel as their earliest point of intervention.

MCA indicated that the participants who graduated in the Middle East, with 1-5 year' experience, preferred traditional class II preparations. The analysis also showed that dentists who graduated from North American universities and those with more than 20 years of experience preferred saucer-shaped preparations, whereas the other dentists appeared to prefer tunnel preparations.

In relation to the earliest stage of occlusal carious development at intervention and demographic factors, the 
MCA indicated that dentists who graduated in the USA and Europe and those with 1-15 years of experience tended to choose stage III or stage IV, dentists who graduated in Asia and those with 6-10 years of experience tended to choose stage III (lesions in the outer third of the dentin on bitewing radiograph), dentists who graduated in the Middle East and those with 16-20 years of experience tended to choose stage IV (lesions in the middle third of the dentin on bitewing radiograph), and dentists with more than 20 years of experience tended to choose stage II (no radiographic sign of carious lesions). The effects of continuing education were not so strong.

MCA also indicated that dentists who graduated from North American universities and those with more than 20 years of experience tended to prefer the sandwich technique; dentists who graduated in Asia tended to choose amalgam or RMGI, dentists who graduated in the Middle East and those with 6-10 years of experience tended to choose RMGI or amalgam, and dentists who graduated from European and Middle Eastern universities and those with up to 20 years of experience tended to choose composite materials.

\section{Discussion}

The studied dentists from clinics of the Ministry of Health of Kuwait tended to delay restorative intervention until dentinal penetration of the caries. Traditional preparation techniques were found to still be in use when restoring approximal lesions. The factors that were most strongly associated with restorative treatment were experience, university of dental education, and participation in continuing education.

Although the treatment strategies for primary occlusal lesions on permanent teeth have generally changed during the past decades from operative treatments towards nonoperative strategies [11], these dentists in $\mathrm{Ku}$ wait preferred restorative treatment of occlusal lesions penetrating dentin. This preference is consistent with other studies which have reported that most dentists still prefer to restorative treatments for such lesions $[8,10-$ 12]. The reason for this practice could be the fact that traditionally the surgical approach was the predominant form of treatment for caries management. Some practicing dentists, especially those who do not participate in continuing education courses, are still following this model.

Overall, dentists tended to delay their initial point of surgical restorative treatment for occlusal lesions only when the lesion was in the inner half of the dentin. However, it has been reported that in France most private general dentists would intervene surgically for lesions confined on the enamel or at the EDJ [3], while only $1 \%$ of dentists in Sweden and 54.5\% of dentists in Brazil [9] would intervene in approximal lesions extending into the enamel. In addition, even given the variability in restorative intervention thresholds, it has been reported that practitioners tend to view the EDJ as the critical decision point for surgical intervention [15-17, 19]. The practitioner responses in this study, with regard to occlusal lesions, reflected a large variability in the identification of points of initial intervention due to the level of experience and participating in continuing dental education courses. Dentists with more experience and who participated in continuing dental education courses started their intervention point earlier. Our findings are similar to those of previous studies $[15-17,20]$ where experience and participation in continuing dental education were reported to be important. These differences could be attributed to multiple factors that include large disparities in the teaching of cariology and restorative dentistry, a wide variability in the diagnosis of carious lesions, assessment of the restorations and treatment decisions reported [21], and the nature of practice [9].

In assessing approximal posterior carious lesions, practitioners tended to display less variability among each other in terms of the initial point of intervention. The majority elected to intervene when radiographic evidence showed that the carious lesion had reached the outer-third layer of dentin or more. This was not affected by the region of the world where they received their dental education or the number of years of experience that they had. A probable explanation for the limited variability observed in this study could be the fact that in cases of approximal lesions, radiographic methods are the primary tools for the assessment of caries detection. Several studies have shown that dentists make a correlation between the appearance on bitewing radiographs and the presence of cavitation [7, 15, 22, 23] for approximal lesions.

For approximal carious lesions the dentists preferred more invasive traditional class II preparations, but for occlusal lesions the majority of the respondents indicated that they would be more conservative and remove the carious tissue only. However, it must be noted that in all situations the practitioners opted for restorative intervention over the more conservative sealant and treatment with fluorides and antimicrobials. These findings reflect the adoption of less conservative surgical restorative interventions. Similar findings have been reported in 
the USA, where conservative, noninvasive management strategies for early occlusal and suspected dentinal caries are not widely adopted by US clinicians [12]. This can be attributed to the fact that the long-term effectiveness of intact sealants in halting the progression of enamel caries remains relatively unknown [12].

The use of composite resin materials was found to be predominant. It is now well established that there is a clear trend towards prioritization of the teaching of posterior composite restorations over amalgam restorations in UK and North American dental schools [24]. In addition, some European countries such as Norway and Sweden have eliminated the use of amalgam as a whole. Therefore, the predominant use of resin materials reported here is most probably due to the majority of participating dentists being recent graduates and the widespread shift in the operative teaching of dental students worldwide [25].
The limitations of this study include: (a) the information gathered in this survey relied primarily on the participants' self-reported practices, (b) the dentists in the study were presented with hypothetical situations, and (c) their responses might not have accurately reflected their daily clinical practices.

\section{Conclusion}

Our findings showed that in the case of occlusal and approximal lesions, participants delayed restorative intervention until dentinal penetration of the caries. Participants chose the conservative approach for occlusal lesions but still believed in the traditional approach regarding approximal lesions. Experience, university dental education, and participation in continuing education courses were associated with restorative treatment.

\section{References}

1 Marcenes W, Kassebaum NJ, Bernabé E, et al: Global burden of oral conditions in 1990 2010. J Dent Res 2013;92:592-597.

$\checkmark 2$ Behbehani JM, Scheutz F: Oral health in Kuwait. Int Dent J 2004;54(suppl 1):401-408.

$>3$ Dennison JB, Hamilton JC: Treatment decisions and conservation of tooth structure. Dent Clin North Am 2005;49:867-887.

$\checkmark 4$ Mount GJ, Ngo H: Minimal intervention: a new concept for operative dentistry. Quintessence Int 2000;31:527-533.

5 McComb D: Systematic review of conservative operative caries management strategies. J Dent Educ 2001;65:1154-1161.

6 Murdoch-Kinch CA, McLean ME: Minimally invasive dentistry. J Am Dent Assoc 2003;134: 87-95.

7 Lynch C, Frazier K, McConnell R, et al: Minimally invasive management of dental caries: contemporary teaching of posterior resinbased composite placement in US and Canadian dental schools. J Am Dent Assoc 2011; 142:612-620.

$>8$ Borges BC, Campos GB, da Silveira AD, et al: Efficacy of a pit and fissure sealant in arresting dentin non-cavitated caries: a 1-year followup, randomized, single-blind, controlled clinical trial. Am J Dent 2010;23:311-316.

$>9$ Fyffe HE, Deery C, Nuttal NM, et al: Effect of diagnostic threshold on the validity and reliability of epidemiological caries diagnosis using the Dundee Selectable Threshold Method for caries diagnosis (DTSM). Community Dent Oral Epidemiol 2000;28:42-51.
10 Pitts NB: Modern concepts of caries measurement. J Dent Res 2004;83:43-47.

11 Bakhshandeh A, Qvist V, Ekstrand KR: Sealing occlusal caries lesions in adults referred for restorative treatment: $2-3$ years of followup. Clin Oral Investig 2012;16:521-529.

-12 Bader JD, Shugars DA: The evidence supporting alternative management strategies for early occlusal caries and suspected occlusal dentinal caries. J Evid Based Dent Pract 2006;6: 91-100.

13 Ekstrand KR, Ricketts DN, Kidd EA, et al: Detection, monitoring and logical treatment of occlusal caries in relation to lesion activity and severity: an in vivo examination with histological validation. Caries Res 1998;32:247254.

14 Sawyer KK, Donly KJ: Remineralization effects of a sodium fluoride biodegradable gel. Am J Dent 2004;17:245-248.

15 Bader JD, Shugars DA: What do we know about how dentists make caries-related treatment decisions? Community Dent Oral Epidemiol 1997;25:97-103.

16 Kay EJ, Locker D: Variations in restorative treatment decisions: an international comparison. Community Dent Oral Epidemiol 1996;24:376-379.
17 Espelid I, Tveit AB: A comparison of radiographic occlusal and approximal caries diagnoses made by 240 dentists. Acta Odontol Scand 2001;59:285-289.

18 Ministry of Health of Kuwait: Dental Administration Statistics. http://www.moh.gov.kw/.

19 Zafersoy-Akarslan Z, Erten H, Uzon O, et al: Reproducibility and agreement of clinical diagnosis of occlusal caries using unaided visual examination and operating microscope. J Can Dent Assoc 2009;75:455.

20 Ismail A: Visual and visuo-tactile detection of dental caries. J Dent Res 2004;83:C56-C66.

21 Tubert-Jeannin S, Domejean-Orliaguet S, Riordan P, et al: Restorative treatment strategies reported by French university teachers. J Dent Educ 2004;68:1096-1103.

22 Espelid I, Tveit A, Haugejorden O, et al: Variation in radiographic interpretation and restorative treatment decisions on approximal caries among dentists in Norway. Community Dent Oral Epidemiol 1985;13:26-29.

-23 Pereira AC, Eggertsson H, Martinez-Mier EA, et al: Validity of caries detection on occlusal surfaces and treatment decisions based on results from multiple caries-detection methods. Eur J Oral Sci 2009;117:51-57.

24 Wilson NH, Lynch CD: The teaching of posterior resin composites: planning for the future based on 25 years of research. J Dent 2014;42:503-516

-25 Griffin SO, Oong E, Kohn W, et al: The effectiveness of sealants in managing caries lesions. J Dent Res 2008;87:169-174. 